\title{
O saneamento ambiental inadequado e sua correlação com hospitalizações
}

No Brasil, uma significativa parcela da população não dispõe de saneamento ambiental adequado. Tal situação resulta em danos ambientais, especialmente em contaminação dos corpos hídricos e do solo, afetando o equilíbrio ambiental e comprometendo a saúde humana. Este estudo teve como objetivo geral: analisar a correlação entre o acesso ao saneamento ambiental (abastecimento de água e esgotamento sanitário) e as hospitalizações. E como objetivos específicos: Demonstrar a evolução do acesso aos serviços de saneamento, no período de 2007 a 2014; Identificar se as soluções individuais ou coletivas de abastecimento de água e esgotamento sanitário estão sendo adequadas para prevenção de DRSAI (Doenças relacionadas ao Saneamento Ambiental Inadequado) e suas complicações: Comparar a ocorrência das hospitalizaç̃es por DRSAl de acordo com a etiologia. A população do estudo foi constituída pelas famílias residentes no estado da Paraíba, de acordo com o IBGE, durante os anos 2007 a 2014 . A amostra foi composta por famílias cadastradas no Programa Saúde da Família, e por usuários do Sistema Único de Saúde, hospitalizados por DRSAI, de acordo com registros do SIHSUS (Sistema de Informações Hospitalares). Os referidos dados foram coletados no portal de informação DATASUS, entre novembro de 2017 a janeiro de 2018, onde foram exploradas informações do Sistema de Informação da Atenção Básica sobre a situação de saneamento; e o SIHSUS. O método utilizado para a análise estatística dos dados foi a correlação de postos de Spearman, para dados não-paramétricos, com significância estatística de $95 \%$ e valor p meno que $0,05(p<0,05)$. Na análise de dados, foi utilizada a estatística descritiva, com o auxílio do software estatístico $R$. Esta pesquisa identificou que o acesso à água por outras formas, além da rede pública e dos poços e nascentes, tem sido uma excelente estratégia para prevenir hospitalizações por parasitoses. Também ficou evidente a importância da ampliação da rede de esgotos na reducão das DRSAl causadas por parasitas, bactérias e vírus. Observamos ainda que as fossas, tal qual estão sendo construídas, não tem sido uma forma segura de descartar os dejetos, pois o uso desta solução individual demonstrou correlação positiva. Este estudo contribui para compreensão da relação entre condições sanitárias e adoecimento; chamando atenção para novos nichos ecológicos eleitos pelo Aedes Aegypti e a importância de soluções individuais de acesso à água potável, bem como a urgência de devida implementação de políticas relacionadas à preservação ambiental.

Palavras-chave:Saneamento; Saúde Ambiental; Hospitalização.

\section{Inadequate environmental sanitation and its correlation with hospitalizations}

In Brazil, a significant portion of the population does not have adequate environmental sanitation. This situation results in environmental damage, especially in contamination of water bodies and soil, affecting the environmental balance and compromising human health. This study had as general objective: to analyze the correlation between access to environmenta sanitation (water supply and sanitary sewage) and hospitalizations. And as specific objectives: Demonstrate the evolution of access to sanitation services, from 2007 to 2014; Identify whether individual or collective water supply and sewage solutions are appropriate for DRSAI (Diseases Related to Inadequate Environmental Sanitation) prevention and its complications; To compare the occurrence of hospitalizations by DRSAl, according to the etiology. The study population consisted of families living in the state of Paraiba, according to the IBGE, during the years 2007 to 2014. The sample was composed of families enrolled in the Family Health Program, and by users of the Unified Health System (SUS), hospitalized by DRSAl according to SHSUS (Hospita In. The sa statistical significance of $95 \%$ and $p$ value less than $0.05(p<0.05)$. In the data analysis, descriptive statistics were used, with the aid of statistical software $R$. This research identified that access to water in other ways, in addition to public water and wells and springs, has been an excellent strategy to prevent hospitalizations for parasitic diseases. It was also evident the importance of expanding the sewage collection system in reducing DRSAI caused by parasites, bacteria and viruses. We also observed that the septic tanks, as they are being constructed, have not been a safe way to discard waste, since the use of this individual solution showed a positive correlation. This study contributes to an understanding of the relationship between sanitary condition and illness; drawing attention to new ecological niches elected by Aedes Aegypti. and the importance of individual solutions for access to drinking water, as well as the urgent need to implement policies related to environmental preservation.

Keywords: Sanitation; Environmental Health; Hospitalization.

Topic: Epidemiologia e Saúde Ambiental

Reviewed anonymously in the process of blind peer.

Luzibênia Leal de Oliveira (ic)

Universidade Federal de Campina Grande, Brasil

http://lattes.cnpq.br/8840173909052565

http://orcid.org/0000-0002-8549-370X

luzibenia@gmail.com

Ângela Maria Cavalcanti Ramalho

Universidade Estadual da Paraíba, Brasil

http://lattes.cnpq.br/7449740069093028

http://orcid.org/0000-0002-8567-4367

angelamcramalho@gmail.com

\section{Patrício Marques de Souza (DD}

Universidade Federal de Campina Grande, Brasil

http://lattes.cnpq.br/0395671025242338

http://orcid.org/0000-0002-2064-3818

patriciomsouza@gmail.com

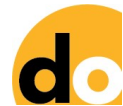

DOI: 10.6008/CBPC2179-6858.2018.005.0007
Received:10/06/2018

Approved:24/07/2018

\author{
Ricardo Olinda (ic \\ Universidade Estadual da Paraíba, Brasil \\ http://lattes.cnpq.br/7767223263366578 \\ http://orcid.org/0000-0002-0509-8428 \\ ricardo.estat@yahoo.com.br \\ Fatima Daniela Lucio Jorge Rocha \\ Universidade Estadual da Paraíba, Brasil \\ http://lattes.cnpq.br/4708373181958402 \\ daniela.lucio@gmail.com

\section{Evelyn Sales Victor} \\ Universidade Federal de Campina Grande, Brasi \\ http://lattes.cnpq.br/8970472177262448 \\ http://orcid.org/0000-0002-9223-2831 \\ enf.evelynsales@gmail.com
}

\section{Referencing this:}

OLIVEIRA, L. L.; RAMALHO, A. M. C.; SOUZA, P. M.; OLINDA, R.; ROCHA F. D. L. J.; VICTOR, E. S.. O saneamento ambiental inadequado e sua correlação com hospitalizações. Revista Ibero Americana de Ciências Ambientais, v.9, n.5, p.64-77, 2018. DOI:

http://doi.org/10.6008/CBPC2179-6858.2018.005.0007 


\section{INTRODUÇÃO}

No Brasil, uma significativa parcela da população urbana não dispõe de saneamento ambiental adequado, especificamente, abastecimento de água e sistema de esgotamento sanitário. Tal situação resulta em danos ambientais, especialmente em contaminação dos corpos hídricos e do solo, afetando o equilíbrio ambiental e comprometendo a saúde humana.

O saneamento ambiental inadequado mantém uma estreita relação com as condições de saúde humana e do meio ambiente e consequentemente com o desenvolvimento de uma sociedade. A ausência ou insuficiência dos serviços essenciais de abastecimento de água e esgotamento sanitário são responsáveis por poluição ambiental e pelo surgimento de doenças, que podem levar ao absenteísmo no trabalho e nas escolas, oneram os gastos com hospitalizações e provocam sérios danos ao meio ambiente. Todos estes problemas podem e devem ser evitados com iniciativas eficientes de saneamento ambiental, bem como, com investimentos em educação para a saúde em todos os espaços sociais pertinentes.

As ações de saneamento ambiental têm como objetivo desenvolver condições ideais de salubridade ambiental, tanto nos centros urbanos quanto nas comunidades rurais, por meio de promoção de abastecimento de água potável, coleta e disposição sanitária de resíduos, promoção da disciplina sanitária do uso, drenagem e ocupação do solo, controle de vetores e reservatórios de doenças transmissíveis, melhorias sanitárias domiciliares, educação sanitária e ambiental e demais serviços especializados (BVS, 2018).

No Brasil, observamos que, embora a rede de abastecimento de água não esteja universalizada, pode ser considerada abrangente, porém, no tocante à rede de esgoto - tanto a coleta quanto o tratamento - encontram-se em situação bastante deficiente. A precariedade destes serviços contribui para a alta incidência de Doenças Relacionadas ao Saneamento ambiental inadequado (DRSAl), sendo considerada também a principal causa de degradação ambiental das bacias hidrográficas brasileiras. Esta situação provoca impactos negativos em diversos campos: educação, trabalho, economia, biodiversidade, disponibilidade hídrica, dentre outros (FERREIRA et al., 2017).

As DRSAI podem estar associadas a não disponibilização de água de boa qualidade, a má disposição dos resíduos sólidos e dos esgotos, às condições precárias de moradia como também um ambiente poluído (MOTA, 2013). Os agentes causadores das DRSAI podem ser parasitas, bactérias e vírus. Neste estudo foram abordadas as seguintes doenças: parasitárias/parasitoses (amebíase, ancilostomíase e esquistossomose), bacterianas (cólera, febre tifóide, febre paratifóide, shiguelose, tracoma e leptospirose) e dengue.

As taxas de morbidade e mortalidade por DRSAI apresentam níveis preocupantes em escala mundial. São doenças consideradas negligenciadas, em função de manter estreita relação com a falta de investimentos adequados no bem-estar e qualidade de vida das comunidades. Especialmente nos países considerados em desenvolvimento, a exemplo do Brasil, as DRSAI vêm ganhando grandes proporções. Elas são disseminadas principalmente em comunidades onde imperam a pobreza, a baixa escolaridade e às más 
condições sanitárias.

Os investimentos em saneamento ambiental não têm acontecido na mesma proporção que surgem os aglomerados urbanos, nem tampouco atende as exigências das necessidades surgidas pelas crises e acidentes ambientais, porém estas situações são primordiais para os gestores e sociedade refletirem sobre este assunto. Neste sentido, Chiarelotto et al. (2017), destacam que fatos marcantes como os acidentes ambientais e conferências mundiais sobre meio ambiente, são primordiais para a construção de um desenvolvimento sustentável e consequentemente maior atenção e investimentos em saneamento básico.

Os grupos que mais sofrem com este grave problema de saúde pública são as crianças, porém os malefícios se estendem a todos os grupos etários e dependendo da doença atinge todas as classes sociais, como é o caso da dengue. Todas são doenças evitáveis, porém, além de apresentarem alta incidência tem se estendido do âmbito do tratamento ambulatorial para o ambiente hospitalar, levando escolares e trabalhadores a se ausentarem dos espaços sociais a que pertencem e ficarem dias internados e em alguns casos inclusive os casos se tornam tão graves que evoluem para o óbito. Esta situação gera perdas para cada indivíduo que adoece, para a comunidade a que pertence, e consequentemente para o desenvolvimento da sociedade.

A associação entre a ausência ou insuficiência dos serviços de saneamento ambiental e o surgimento de doenças é notório, porém estudos que demonstrem o quão preocupante tem se tornado esta questão, são pertinentes e fundamentais para entender sua gravidade. Tal agravamento é evidenciado pela necessidade de internação hospitalar, sugerindo também a ausência de atendimento precoce e correto nos serviços de saúde no âmbito da atenção básica.

No cenário estadual, a situação da Paraíba não é diferente, tendo em vista que várias são as doenças verificadas e o serviço de abastecimento de água e esgotamento sanitário é problemático, levando a necessidade de ações para uma gestão mais qualificada que traga eficácia e eficiência nos seus serviços, bem como, se faz necessário também uma investigação científica aprofundada sobre o tema de modo a contribuir academicamente e socialmente.

Diante do exposto, este estudo teve como objetivo geral analisar a correlação entre o acesso ao saneamento ambiental (abastecimento de água e esgotamento sanitário) e as hospitalizações. E como objetivos específicos: demonstrar a evolução do acesso aos serviços de saneamento, no período de 2007 a 2014; identificar se as soluções individuais ou coletivas de abastecimento de água e esgotamento sanitário estão sendo adequadas para prevenção de DRSAI e suas complicações; comparar a ocorrência das hospitalizações por DRSAI, de acordo com a etiologia.

\section{METODOLOGIA}

O estudo aconteceu no Estado da Paraíba, que se situa a leste da Região Nordeste do Brasil e tem como limites, ao norte o estado do Rio Grande do Norte, a leste o Oceano Atlântico, ao sul Pernambuco e a oeste o Ceará. Segundo a estimativa de 2014, do Instituto Brasileiro de Geografia e Estatística (IBGE), o Estado da Paraíba possui uma população de 3.943 .885 habitantes distribuída em uma área de 56.469 km², 
totalizando uma densidade demográfica de 69,84 habitantes $/ \mathrm{km}^{2}$. Apresenta uma maior concentração populacional na área urbana (75\%) em relação à área Rural (25\%). Em relação ao sexo, 48,4\% (1.824.379) da população paraibana é composta de homens e 51,6\% (1.942.149) de mulheres (PARAÍBA, 2016; IBGE, 2014).

A população foi constituída pelas famílias residentes no estado da Paraíba, de acordo com o IBGE, durante os anos 2007 a 2014. E a amostra foi composta por famílias cadastradas no Programa Saúde da Família (PSF), e por usuários do SUS (Sistema Único de Saúde) internados em ambiente hospitalar devido às DRSAI, de acordo com registros do SUS (SIHSUS). Os referidos dados foram coletados no portal de informação DATASUS, onde foram exploradas informações do SIAB (Sistema de Informação da Atenção Básica) sobre a situação de saneamento; e exploramos as informações de saúde, e o SIHSUS (Sistema de Informações Hospitalares).

O SIAB foi implantado para o acompanhamento das ações e dos resultados das atividades realizadas pelas equipes do Programa Saúde da Família (PSF). Através dele obtêm-se informações sobre cadastros de famílias, condições de moradia e saneamento, situação de saúde, produção e composição das equipes de saúde. No tocante a finalidade do SIHSUS, ele permite registrar todos os atendimentos provenientes de hospitalizações que foram financiadas pelo SUS (BRASIL, 2018). Especificamente para esta pesquisa, exploramos o SIHSUS para identificar dentre todas as causas de hospitalizações aquelas que foram por doenças relacionadas ao saneamento ambiental inadequado.

Dentre as DRSAI pesquisadas no SIHSUS, a dengue foi identificada como única doença viral relacionada ao saneamento ambiental indadequado. Os dados foram coletados no período de Dezembro de 2017 à Janeiro de 2018. Obedecemos à seguinte sequência de busca no Portal de Informação DATASUS: <Informações de Saúde (TABNET)+Epidemiológicas e de Morbidade+Morbidade Hospitalar do SUS (SIHSUS)+ por local de residência>. A consulta ao sistema do Tabnet foi realizada no período de março a junho de 2017.

O método utilizado para a análise estatística dos dados foi a correlação de postos de Spearman (SIEGEL, 2006), para dados não-paramétricos, com significância estatística de 95\% e valor p menor que 0,05 $(p<0,05)$. Foram correlacionadas as seguintes variáveis independentes: doenças parasitárias/parasitoses, doenças bacterianas e dengue com as variáveis dependentes: destino dos dejetos; abastecimento de água; poço/nascente e outros.

$\mathrm{Na}$ análise de dados, foi utilizada a estatística descritiva, utilizando frequências simples absolutas e percentuais para as variáveis categóricas e organização dos resultados. Para verificar possíveis correlações entre as variáveis em estudo, tendo em vista que as variáveis não seguiram o comportamento normal, foi utilizado o teste de correlação de Spearman (p) (SIEGEL, 2006), considerando o nível de significância de 5\% $(p<0,05)$. As análises foram realizadas com o auxílio do software estatístico R (R CORE TEAM, 2017).

\section{RESULTADOS}

Os dados apresentados na Tabela 1 descrevem a distribuição percentual de famílias cadastradas no 
SIAB, com relação ao destino dos dejetos e as formas de acesso a água, no periodo de 2007 a 2014, no estado da Paraíba.

Tabela 1: Distribuição percentual de famílias cadastradas no SIAB, com relação ao destino dos dejetos e as formas de acesso a água, no período de 2007 a 2014, no estado da Paraíba.

\begin{tabular}{|l|l|l|l|l|l|l|l|}
\hline & \multicolumn{3}{|l|}{ REDE PÚBLICA } & \multicolumn{2}{l|}{ POÇO/NASCENTE } & OUTROS \\
\hline ANO & FAMÍLIAS & TOTAL & $\%$ & TOTAL & $\%$ & TOTAL & $\%$ \\
\hline $\mathbf{2 0 0 7}$ & 905.126 & 627.745 & $69,35 \%$ & 162.170 & $17,92 \%$ & 115.472 & $12,76 \%$ \\
\hline $\mathbf{2 0 0 8}$ & 916.470 & 642.251 & $70,08 \%$ & 160.432 & $17,51 \%$ & 113.784 & $12,42 \%$ \\
\hline $\mathbf{2 0 0 9}$ & 962.641 & 695.125 & $72,21 \%$ & 155.465 & $16,15 \%$ & 112.050 & $11,64 \%$ \\
\hline $\mathbf{2 0 1 0}$ & 1.046 .140 & 748.103 & $71,51 \%$ & 175.359 & $16,76 \%$ & 122.677 & $11,73 \%$ \\
\hline $\mathbf{2 0 1 1}$ & 988.033 & 722.575 & $73,13 \%$ & 153.282 & $15,51 \%$ & 112.176 & $11,35 \%$ \\
\hline $\mathbf{2 0 1 2}$ & 1.004 .161 & 742.314 & $73,92 \%$ & 151.336 & $15,07 \%$ & 110.511 & $11,01 \%$ \\
\hline $\mathbf{2 0 1 3}$ & 1.025 .739 & 768.611 & $74,93 \%$ & 149.730 & $14,60 \%$ & 107.398 & $10,47 \%$ \\
\hline $\mathbf{2 0 1 4}$ & 940.763 & 708.237 & $75,28 \%$ & 135.631 & $14,42 \%$ & 96.895 & $10,30 \%$ \\
\hline
\end{tabular}

No tocante a destinação dos dejetos é nítida a carência de redes de esgotos. As soluções individuais, fossa e céu aberto, ainda imperam no estado, assumindo uma média de $64,04 \%$. A questão do abastecimento de água tem evoluído mais rapidamente do que o esgotamento sanitário, uma média de $70,05 \%$ das famílias pesquisadas tem acesso à rede pública, enquanto $29,94 \%$ recorrem à poços/nascentes e outras formas. A Tabela 2 apresenta o número absoluto de hospitalizações por DRSAl agrupadas de acordo com a classificação referente ao agente causador (parasitárias, bacterianas e dengue), no período de 2007 a 2014, no estado da Paraíba.

Tabela 2: Número absoluto de hospitalizações por DRSAl agrupadas de acordo com a classificação referente ao agente causador (parasitárias, bacterianas e virais/dengue), no período de 2007 a 2014, no estado da Paraíba.

\begin{tabular}{|l|l|l|l|}
\hline & Número de hospitalizações por DRSAI & Bacterianas & Virais \\
\hline Ano & Parasitárias & 36 & 1952 \\
\hline $\mathbf{2 0 0 7}$ & 80 & 352 & 2536 \\
\hline $\mathbf{2 0 0 8}$ & 223 & 176 & 638 \\
\hline $\mathbf{2 0 0 9}$ & 259 & 138 & 2249 \\
\hline $\mathbf{2 0 1 0}$ & 277 & 55 & 2483 \\
\hline $\mathbf{2 0 1 1}$ & 232 & 26 & 1322 \\
\hline $\mathbf{2 0 1 2}$ & 210 & 40 & 1768 \\
\hline $\mathbf{2 0 1 3}$ & 134 & 25 & 1042 \\
\hline $\mathbf{2 0 1 4}$ & 146 & 84 & 13990 \\
\hline Total & 1561 & & \\
\hline
\end{tabular}

Percebemos que a dengue é a principal DRSAI que tem evoluído para internação hospitalar, destacando-se com uma média de 1748,75 pessoas acometidas pela doença e hospitalizadas pelo SUS, para o período de 2007 a 2014. As doenças parasitárias e bacterianas totalizaram uma média de 195,13 e 106 internaçoes hospitalares, respectivamene, para o periodo estudado. Ao correlacionarmos as internações por DRSAl e formas de acesso à água, no período de 2007 a 2014, verificamos correlação e significância apenas entre hospitalizações por parasitoses e outras formas de acesso (Tabela 3). Quando aplicamos o teste de correlação entre as variáveis: hospitalizações por DRSAl e destinação dos dejetos, encontramos tanto correlação quanto significância em cinco situações, quais sejam: parasitoses e esgotos; parasitoses e fossas; doenças bacterianas e esgotos; dengue e esgoto; dengue e fossa (Tabela 4). 
Tabela 3: Correlacão entre internações por DRSAl e formas de acesso à água, no período de 2007 a 2014 , no estado da Paraíba.

\begin{tabular}{|c|c|c|c|c|c|c|c|c|c|}
\hline \multirow[b]{3}{*}{ Causas de Internação } & \multicolumn{9}{|c|}{ Formas de acesso à água } \\
\hline & \multicolumn{3}{|c|}{ Rede Pública } & \multicolumn{3}{|c|}{ Poço/Nascente } & \multicolumn{3}{|l|}{ Outras } \\
\hline & $\mathrm{S}$ & $\mathrm{p}$ & $\rho$ & $\mathrm{S}$ & $\mathrm{p}$ & $\rho$ & $\mathrm{S}$ & $\mathrm{p}$ & $\rho$ \\
\hline Parasitárias & 3833,10 & 0,098 & 0,297 & 3980,30 & 0,134 & 0,270 & 8389,00 & 0,002 & 0,538 \\
\hline Bacterianas & 6717,20 & 0,203 & $-0,231$ & 5798,60 & 0,733 & $-0,063$ & 5136,40 & 0,750 & 0,059 \\
\hline Dengue & 5490,00 & 0,980 & $-0,005$ & 5481,00 & 0,980 & $-0,005$ & 6348,20 & 0,371 & $-0,164$ \\
\hline
\end{tabular}

Tabela 4:Correlacão de Spearman ( $\rho)$, com as respectivas estatísticas (S) e valores de $p$ (valor-p), entre internações por DRSAl e destinação dos dejetos, no período de 2007 a 2014, no estado da Paraíba.

\begin{tabular}{|c|c|c|c|c|c|c|c|c|c|}
\hline \multirow[b]{3}{*}{ Causas de Internação } & \multicolumn{9}{|c|}{ Formas de destinação dos dejetos } \\
\hline & \multicolumn{3}{|l|}{ Esgoto } & \multicolumn{3}{|l|}{ Fossa } & \multicolumn{3}{|c|}{ Céu aberto } \\
\hline & $S$ & valor $p$ & $\rho$ & $S$ & valor $p$ & $\rho$ & $S$ & valor $p$ & $\rho$ \\
\hline Parasitárias & 9043,6 & $4,33 e-05$ & $-0,658$ & 3014,2 & 0,0102 & 0,448 & 5571,3 & 0,909 & $-0,021$ \\
\hline Bacterianas & 7703,9 & 0,019 & $-0,412$ & 3872,2 & 0,107 & 0,290 & 5093,4 & 0,718 & 0,066 \\
\hline Dengue & 8626,6 & $4,87 e-4$ & $-0,581$ & 2462,5 & 0,0011 & 0,549 & 5972,1 & 0,607 & $-0,095$ \\
\hline
\end{tabular}

No que se refere à correlação entre hospitalizações por parasitoses e outras formas de acesso à água, o teste de Spearman apontou correlação negativa $(\rho=0,54)$, visualizada no Grafico 1, observando-se que a correlação foi estatisticamente significativa $(p<0,05)$, portanto quando o acesso à água por outras formas, a exemplo de carros pipa, cisternas; as hospitalizações por parasitoses diminuem. Esta constatação nos leva a refletir sobre a importância de programas que viabilizam o acesso à água potável, a exemplo do P1MC (Programa um Milhão de Cisternas) e do Operação Carro Pipa (OCP), que ajudam especialmente à população rural do semi-árido brasileiro.

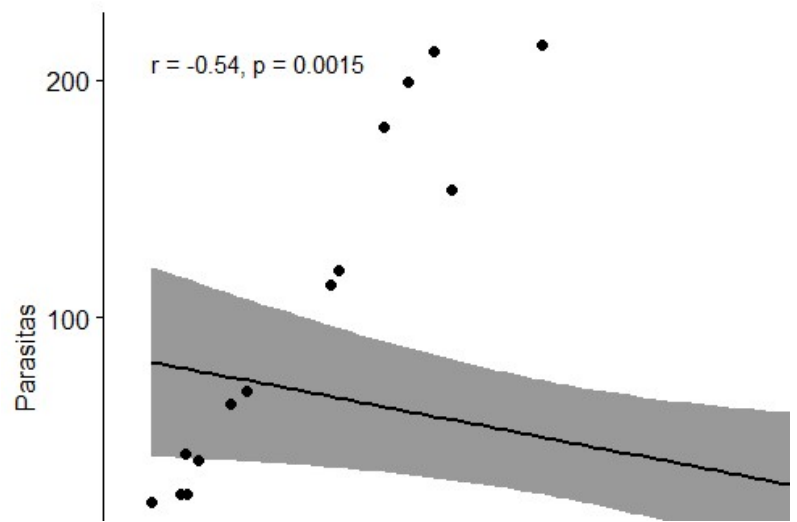

Gráfico 1: Diagrama de dispersão relacionado à correlação entre hospitalizações por parasitoses e outras formas de acesso à água.

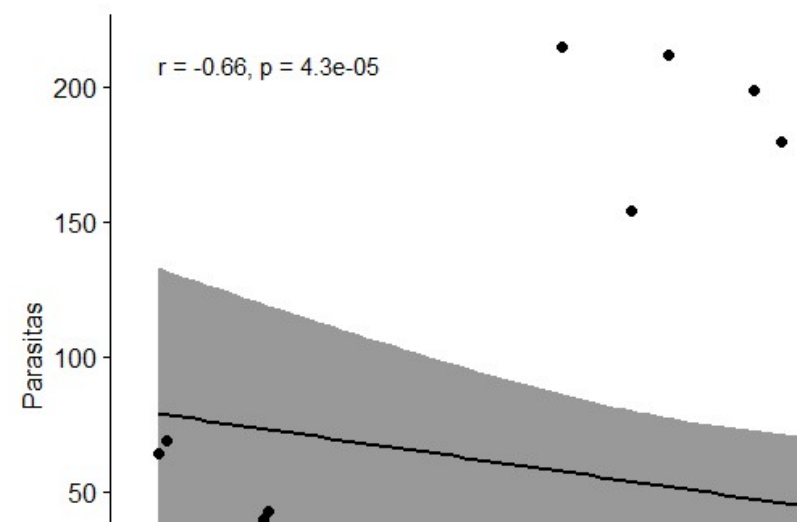

Gráfico 2: Diagrama de dispersão relacionado à correlação entre as hospitalizações por parasitoses e destinação dos dejetos em rede de esgotos.

Analisando a correlação entre as hospitalizações por parasitoses e a destinação dos dejetos em esgotos, o teste de Spearman apontou correlação negativa $(\rho=0,66)$, evidenciada no gráfico 2 com significância de $95 \%$ e $p=4,3$ e-5. Desta forma, a medida que o esgotamento sanitário através da rede pública é ampliado, alcançando um maior número de residências, as hospitalizações por parasitoses reduzem.

A correlação entre hospitalizações por parasitoses e descarte dos dejetos em fossa apresentou-se positiva $(\rho=0,45)$, conforme demonstramos no gráfico 3 , observando-se que a correlação foi estatisticamente significativa $(p<0,05)$ valor $p=0,01$, Constatamos, portanto que à medida que a destinação 
dos dejetos em fossas aumenta, aumentam também o número de internações por DRSAI, esta constatação nos permite inferir que a construção das fossas não está obedecendo às normas mínimas necessárias de engenharia sanitária e ambiental, sugerindo que pelo menos a maioria é do tipo rudimentar, onde o contato dos dejetos com o solo é direto e por sua vez microorganismos patogênicos contaminam toda a área adjascente inclusive o lençol freático.

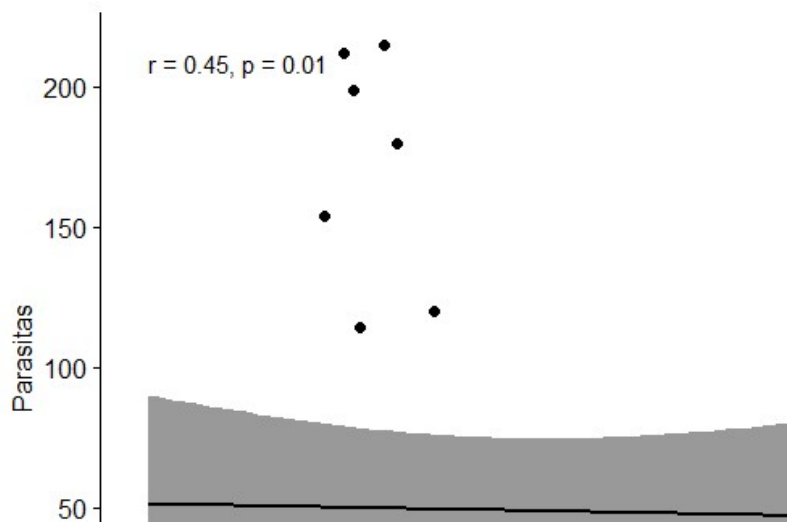

Gráfico 3: Diagrama de dispersão relacionado à correlação entre as hospitalizações por parasitoses e disponibilização dos dejetos em fossas.

Para estas variáveis - doenças bacterianas e a destinação dos dejetos em rede esgoto - o teste de Spearman apontou uma correlação negativa ( $\rho$-0,4120083), observando-se que a correlação foi estatisticamente significativa $(p<0,05)$ e valor $p=0,01912$, conforme demonstramos no Gráfico 4 , com estes resultados é possível entender que à medida que aumenta o esgotamento sanitário, diminuem as hospitalizações por doenças bacterianas.

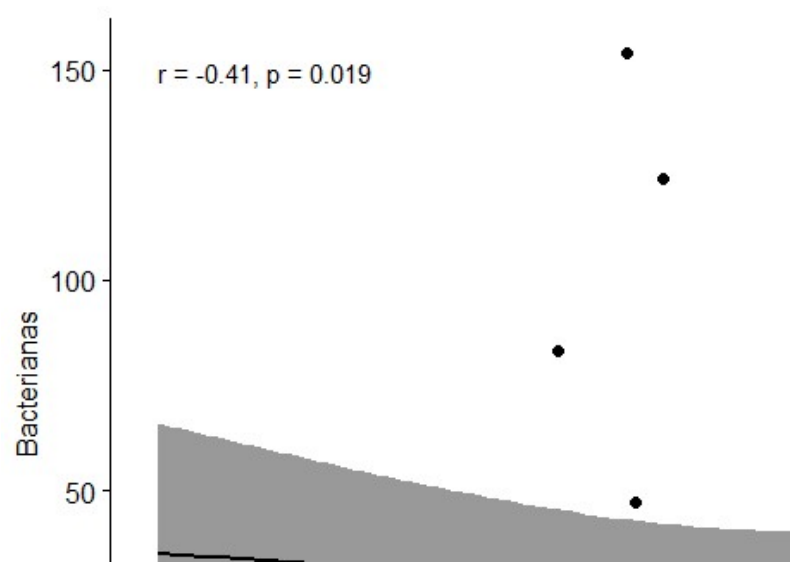

Gráfico 4: Diagrama de dispersão relacionado à correlação entre as hospitalizações por doenças bacterianas e disponibilização dos dejetos em rede de esgoto.

Ao procedermos à análise de correlação entre hospitalizações por Dengue e a disponibilização dos dejetos em rede de esgoto, identificamos uma correlação negativa ( $\rho-0,5811182)$, observando-se que a correlação foi estatisticamente significativa $(p<0,05)$ e valor $p=0,0004873$, exibida no Gráfico 5 , ou seja, percebemos que o aumento no esgotamento sanitário diminuiu as hospitalizações por dengue. 


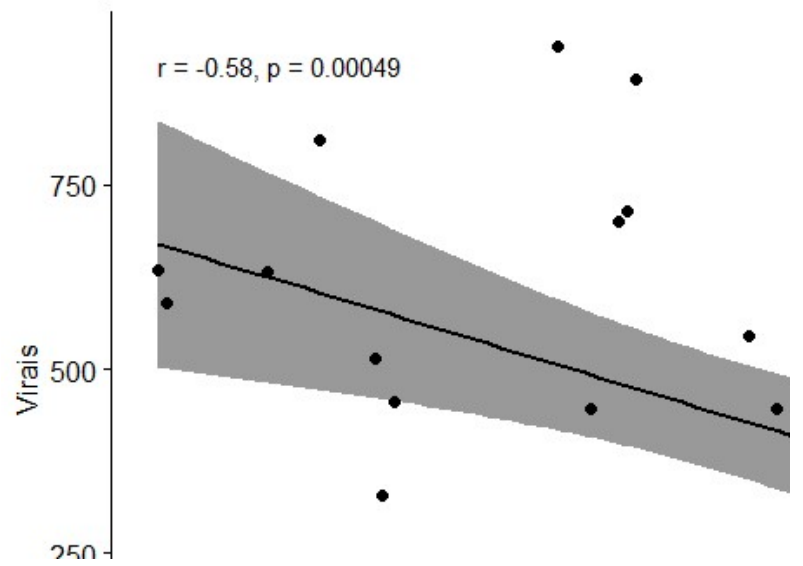

Gráfico 5: Diagrama de dispersão relacionado à correlação entre as hospitalizações por dengue e a disponibilização dos dejetos em rede de esgoto.

Analisando a correlação entre as hospitalizações por dengue e o descarte dos dejetos em fossa, o teste estatístico apontou uma correlação positiva ( 0,548671$)$, observando-se que a correlação foi estatisticamente significativa $(p<0,05)$ e valor $p 0,001148$, demonstrados no Gráfico 6. O aumento na destinação dos dejetos em fossa aumentou o número de hospitalizações por dengue.

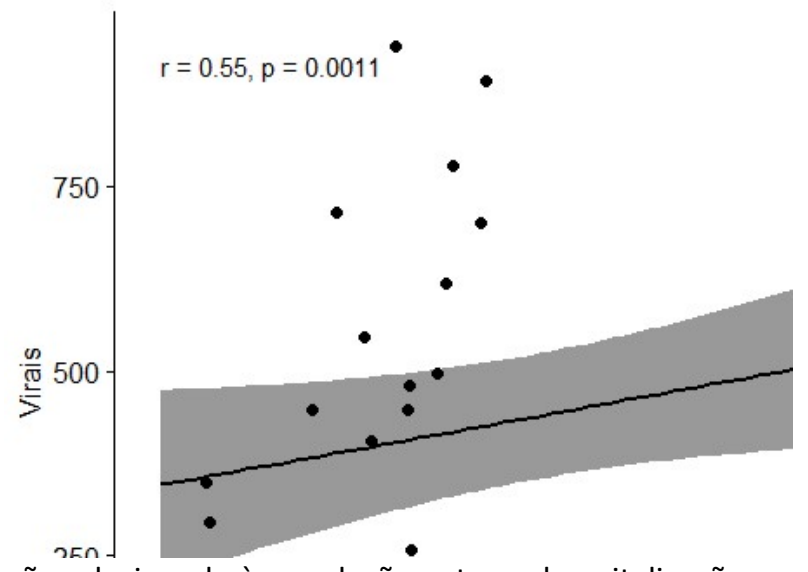

Gráfico 6: Diagrama de dispersão relacionado à correlação entre as hospitalizações por dengue e a disponibilização dos dejetos em fossa.

Ao contaminar o solo, a água e os alimentos, os dejetos humanos descartados inadequadamente em fossas trazem desequilíbrio ambiental e causam enfermidades. Ficou demonstrado com os resultados deste estudo, que as fossas, destino utilizados por muitas famílias nas diversas classes econômicas, tem sido uma solução ineficiente e mais do que isto, tem se estabelecido como um novo nicho ecológico na proliferação de vetores, contaminação do solo e mananciais ao ponto de culminar em um número preocupante de hospitalizações, especialmente por parasitoses e dengue.

\section{DISCUSSÃO}

Esta pesquisa identificou que o acesso à água por outras formas, além da rede geral e dos poços e nascentes, tem sido uma excelente estratégia para prevenir hospitalizações por parasitoses. Também ficou evidente a importância da ampliação da rede de esgotos na redução das DRSAI causadas por parasitas, bactérias e vírus. Observamos ainda que as fossas, tal qual estão sendo construídas, não tem sido uma forma segura de descartar os dejetos, pois o uso desta solução individual demonstrou correlação positiva. 
No semiárido brasileiro dois programas se destacam viabilizando o acesso à água potável: 0 Programa Um Milhão de Cisternas (P1MC) e o Operação Carro Pipa (OCP). O P1MC foi o primeiro programa desenvolvido pela ASA (Articulação Semiárido Brasileiro), no início dos anos 2000, tendo como objetivo principal melhorar a vida das famílias que vivem na Região Semiárida do Brasil, garantindo o acesso à água de qualidade. Através do armazenamento de água da chuva em cisternas construídas com placas de cimento ao lado da casa, as famílias passam a ter água potável sem requerer muito esforço - isto é considerado como um processo de descentralização e democratização da água (ASA BRASIL, 2018).

O OCP, criado pelo Governo Federal em 2005, sob o nome oficial - Programa Emergencial de Distribuição de Água; tem o objetivo de complementar a distribuição de água que está sendo realizada pelos governos estaduais e municipais nas regiões em situação de emergência, a partir da distribuição dos recursos alocados pelo Ministério da Integração Nacional, com fins de planejar, coordenar e fiscalizar, a busca, o transporte, a desinfecção e a distribuição de água potável, contando para isso com a utilização de carros-pipa contratados. Este programa atua nas áreas atingidas pela seca, nos municípios que decretaram emergência ou estado de emergência, na região Nordeste, norte de Minas Gerais e norte do Espírito Santo.

Este achado científico demonstra a importância das comunidades desassistidas pelas soluções coletivas de acesso à água potável, situaçã̃o especialmente comum nas comunidades rurais, buscarem soluções individuais para ter água de boa qualidade em suas residências, bem como dos governos implementarem políticas e programas que estimulem o uso de água em quantidade e qualidade adequadas ao bem estar e a saúde individual e coletiva.

No concernente a correlação entre hospitalizações DRSAl e esgotos, esta pesquisa corrobora com outros estudos amplamente divulgados na literatura científica. É nítida a correlação negativa entre estas variáveis, portanto a análise comprova que a ampliação da rede de esgotos reduz o número de hospitalizações por doenças de origem parasitária, bacteriana e viral. Destacamos dentre as DRSAI estudadas a cólera, que não houve notificação de acordo com o SINAN no período escolhido para o estudo, porém houve registro de 352 hospitalizações, denotando inconsistência e incompatibilidade nos sistemas de informação, mas principalmente alerta a todos para a convivência com uma doença de extrema gravidade.

Um estudo realizado por Gomes et al. (2016), revela a prevalência de parasitoses intestinais, com destaque para Ascaris Lumbricoides em crianças residentes em áreas periféricas e carentes do município de Grajaú, Maranhão; indicando como principais responsáveis por este problema, as más condições de saneamento ambiental, as quais facilitam a contaminação fecal e a transmissão orofecal dos parasitas, comuns pela disposição inadequada dos dejetos e escassez de água, situações estas que favorecem más práticas de higiene, Neste sentido, o acesso ao esgotamento sanitário e a água em quantidade apropriada previnem comprovadamente as parasitoses.

Relaciona-se também com o estudo em questão, uma pesquisa publicada por Busato et al. (2014) com usuários do SUS, em nível de Atenção Básica, no município de Chapecó, Santa Catarina, onde os autores revelam que a maioria das famílias $(88,2 \%)$ não possuía sistema de esgotos em suas residências e 
faltava abastecimento de água pela rede pública para 18,9\%. As menores prevalências de parasitoses foram identificadas nas famílias residentes em áreas com melhores condições de saneamento ambiental e o risco de contaminação por algum parasita chega a ser 9,3\% menor comparado às residentes em áreas com piores condições de saneamento ambiental. Estes achados demonstram que o acesso aos serviços como abastecimento de água e esgotamento sanitário estão estreitamente ligados à prevalência de parasitoses.

Os dois estudos supramencionados reforçam a correlação negativa demonstrada por esta pesquisa, enfatizando o importante papel do acesso ao serviço de esgotamento sanitário na promoção na prevenção de doenças parasitárias. As quais, mesmo atualmente, permanecem sendo negligenciadas, e seguem ocasionando hospitalizações e óbitos.

Mundialmente os avanços científicos e tecnológicos avançam a passos largos, mas países considerados em desenvolvimento que não conseguiram efetivar sua transição epidemiológica ${ }^{1}$ continuam a sofrer com doenças evitáveis, a exemplo das parasitoses.

As DRSAI de etiologia bacteriana transmitidas por via feco-oral, vêm atravessando os séculos e provocando inclusive alta taxa de mortalidade em várias faixas etárias, em função da inacessibilidade aos serviços essenciais de abastecimento de água e esgotamento sanitário, a falta ou mesmo a insuficiência destes serviços, que dificultam a manutenção de boas práticas de higiene, promovem proliferação de vetores, contamina o solo, dentre outros problemas que facilitam o surgimento de doenças.

Araújo et al. (2016) fizeram uma pesquisa que corrobora com os nossos resultados, pois aborda a espacialização dos serviços básicos de saneamento na zona rural do município do sertão paraibano. Nele os autores verificaram percentuais inferiores a $20 \%$ na zona rural daquele município, o que é considerado péssimo. A falta ou precariedade de um sistema de esgotamento sanitário é considerado um dos principais problemas ambientais da nossa sociedade. A garantia deste serviço é indispensável à saúde, pois previne especialmente as doenças de transmissão feco-orais, a exemplo de: febres entéricas (tifóide e paratifóide), salmoneloses, cólera, shiguelose, yersinose, diarreias e disenterias.

Samba (2015), pesquisou a vigilância epidemiológica de doenças infecciosas de origem bacteriana, e destaca a alta incidência da febre tifóide especialmente entre a população jovem ( 0 a 20 anos), relacionando este achado com educação sanitária deficiente, residentes em locais carentes de saneamento ambiental e precários em condições de higiene.

As famílias que não têm acesso aos serviços coletivos de saneamento ambiental precisam utilizar soluções individuais, no quesito destinação dos dejetos é bastante comum a utilização de fossas. A fossa séptica é considerada um destino correto de descarte de dejetos, pois atende a critérios arquitetônicos e sanitários que evitam o contato direto das fezes e urinas com o solo e lençol freático. Porém, além de se preocupar com a estrutura construída, a periódica limpeza e manutenção é essencial para que seja efetivada a prevenção de DRSAI. Cabe também destacar, que outra situação é ainda mais preocupante - a

\footnotetext{
${ }^{1}$ Transição epidemiológica: De acordo com Omran (2005),a transição epidemiológica caracteriza-se pela evolução progressiva de um perfil de alta mortalidade por doenças infecciosas para um outro onde há predominância dos óbitos por doenças crônico-degenerativas, englobando basicamente três mudanças básicas, a saber: a) substituição das doenças transmissíveis por doenças não transmissíveis e causas externas; b) deslocamento da carga de morbimortalidade dos grupos mais jovens para os grupos mais idosos; c) transformação de uma situação em que predomina a mortalidade para outra onde a morbidade é dominante.
} 
existência das fossas rudimentares - onde apenas um buraco escavado no chão torna-se o depósito dos dejetos gerados por muitas famílias, provocando sérios ao meio ambiente e à saúde humana.

O SIAB não fornece essa distinção entre os tipos de fossa, por isso não temos como precisar quantas famílias utilizam fossa séptica ou fossa rudimentar, ou mesmo se os cuidados necessários de manutenção das fossas são realizados adequadamente. Todavia, os resultados encontrados nos testes de correlação aqui aplicados demonstram que seguramente esta forma de destinação não tem sido eficiente na prevenção de DRSAl evidenciada pelo expressivo número de hospitalizações.

Neste sentido, um estudo realizado por Cirqueira Jr et al.(2015) em comunidade quilombola do município de Diamantina, Minas Gerais, identificou que $52,4 \%$ das residências não dispunham de banheiros, por este motivo seus moradores destinavam seus dejetos no peridomicílio, sendo que $23,8 \%$ destinavam em fossas rudimentares e os outros $23,8 \%$ no rio próximo.Ficou comprovado que estas formas de destinação dos dejetos possibilitam a manutenção da contaminação ambiental tanto por ovos de helmintos como por cistos de protozoários e além disso, tal contaminação viabiliza o desenvolvimento de formas larvais de helmintos cuja via de transmissão é transcutânea.

Também mantém relação com nossos achados, um estudo realizado por Reuter et al. (2015), sobre a frequência de parasitoses intestinais, no qual foi identificado que $35,5 \%$ das famílias pesquisadas destinavam seus dejetos em fossas e este fato demonstrou uma forte associação com o surgimento de parasitoses, especialmente Giárdia Lamblia e Ascaris Lumbricoides.

Destarte, as pesquisas realizadas por Cirqueira Júnior et al. (2015) e por Reuter et al. (2015), semelhante aos resultados encontrados, confirmam que mesmo nos dias atuais, uma parcela significativa da população não dispõe de saneamento ambiental e ainda disponibiliza os dejetos em fossas rudimentares, este fato certamente tem contribuído para o surgimento de infecções parasitárias, que muitas vezes evoluem clinicamente com complicações e estes indivíduos passam a necessitar de serviços hospitalares complexos, onerosos e nem sempre suficientemente eficientes.

A falta de esgotamento sanitário também apresenta estreita relação com doenças transmitidas por vetores, como a Dengue, visto que na ausência da rede de esgotos, a água acumulada nas proximidades das residências se torna ambiente propício para a proliferação de vetores, já adaptados também à água suja. Dessa forma, a sociedade precisa se proativa e utilizar a educação ambiental e o exercício da cidadania para lutar por ações de saneamento ambiental que tornem os ambientes onde vivem limpos e salubres.

De acordo com os resultados de um estudo realizado por Linhares et al. (2006) na Zona Oeste do Rio de Janeiro, os bairros com maior predisposição aos surtos de dengue foram aqueles que apresentaram as piores condições de saneamento ambiental, com percentuais significativos de domicílios que não se enquadraram nas categorias de rede geral e fossa séptica. Cabe ressaltar que foram considerados como rede geral, as ligações de domicílios às canalizações que despejam o esgoto diretamente no leito dos rios in natura passando apenas por uma primeira etapa de tratamento, modelo que está longe dos parâmetros ideais sanitários e que põem em risco a qualidade de vida urbana.

Nesta mesma linha, Silva et al. (2017) realizaram uma pesquisa confirmando que a ineficiência do 
saneamento ambiental, quando se trata de esgoto a céu aberto é um fator importante para a proliferação da dengue e de outras enfermidades, pois possibilita o acúmulo de água parada mesmo após o período de chuvas. Essa ocorrência é um problema de saúde pública, pois se tornam ambientes insalubres que transmitem odores, proporcionam a proliferação de doenças, impedem a circulação das pessoas, além de tornarem-se criadouros para animais peçonhentos, roedores, e vetores, como o Aedes aegypti. Nazareno et al. (2016) chamam atenção para o direcionamento do olhar dos governos e da intensificação das medidas de combate à dengue nas estações chuvosas, uma vez passado este período os números de casos da doença diminuem, e o problema volta a ser esquecido até o próximo recrudescimento.

Os autores supramencionados ainda destacam que enquanto perdurar um quadro tão caótico e precário do saneamento ambiental no País, doenças e epidemias permanecerão causando inúmeras vítimas, a despeito de quaisquer medidas urgentes de combate ou do lançamento de plano. Combater o vetor é inegavelmente necessário, mas urgente mesmo é eliminar o atraso em que ainda vive o Brasil, no tocante aos serviços de abastecimento de água, coleta e tratamento de esgoto e gerenciamento de resíduos sólidos.

O vetor da dengue, responsável por promover tanta morbimortalidade em nosso país, tem se mostrado capaz de desenvolver-se até nos ambientes mais inóspitos, como é o caso das fossas, por este motivo, as campanhas e programas de combate a esta enfermidade precisam contemplar em suas ações medidas que disseminem o Aedes Aegypti nestes espaços também. Aliás, diga-se de passagem, todos os protocolos que envolvam este potente vetor, devem ser constantemente atualizados de forma a acompanhar a capacidade e velocidade de adaptação tão versátil deste mosquito.

Comprovando esta tese, estudos desenvolvidos por Corrêa et al. (2015) e Beserra et al. (2014) identificaram a adaptação do Aedes Aegypti às fossas, elegendo-o como novo nicho ecológico. Este fato pode agravar ainda mais o sério problema de saúde pública instalado há diversos anos em nosso país - a epidemia de dengue - principalmente na periferia dos grandes centros urbanos onde o esgotamento sanitário é precário, fato que impõe cada vez mais dificuldade para o estabelecimento de programas de controle baseados em seu monitoramento.

Um fato que cabe destaque e merece atenção das autoridades pertinentes é a ausência de orientação técnica pelo Programa Nacional de Controle da Dengue nas fossas, estes locais têm sido apontados como criadouros altamente produtivos para o Aedes Aegypti, em função disto, esta forma de destinação de dejetos pode ser responsabilizada por manter uma alta densidade populacional deste vetor, independente da realização de campanhas de controle de forma contínua e regular (GIL et al., 2015).

Nossos resultados demonstram uma evolução lenta do setor de saneamento, especialmente na coleta e tratamento dos esgotos e comprovam a correlação desta situação com o surgimento e agravamento de diversas DRSAI, por este motivo urge a necessidade de efetiva implementação das políticas públicas vigentes, bem como adequação de programas nacionais para poder atender as novas exigências, como é o caso de orientações em relação às arboviroses. 


\section{CONCLUSÕES}

Com relação aos serviços de saneamento, no período de 2007 a 2014 percebemos um aumento do acesso das famílias à rede pública ao passo que o acesso através de poços/nascentes e outras formas diminuíram. As soluções individuais para aquisição de água potável tem sido uma excelente estratégia na prevenção de doenças parasitárias e consequentemente hospitalizações devido as complicações das mesmas. Porém, no que se refere a destinação dos dejetos, as fossas não tem sido uma alternativa eficiente; comprovamos que esta solução individual tem se correlacionado positivamente com as hospitalizações por DRSAI.

Comprovamos que a ampliação da rede de esgotos reduz as hospitalizações por parasitoses, doenças bacterianas e dengue. Assim ressaltamos a urgente necessidade de universalização desses serviços que são capazes de não só prevenir doenças, mas reduzir gastos com o restabelecimento da saúde, melhorar a economia do país e combater mortes por causas completamente evitáveis. A pesquisa evidenciou que a dengue foi a patologia com maior número de hospitalizações, denunciando a precariedade das condições sanitárias que uma parcela significativa da população está exposta.

Na Paraíba, assim como no Brasil, uma significativa parcela da população urbana não dispõe de abastecimento de água e sistema de esgotamento sanitário de forma adequada, resultando no agravamento da situação sanitária, que afeta diretamente a saúde humana e do meio ambiente. A valorização dos serviços de saneamento e implementação efetiva da Política de Saneamento trará benefícios imensuráveis, especialmente no âmbito da saúde, quer seja humana ou ambiental.

Assim, este estudo vem contribuir para uma melhor compreensão da relação entre condições sanitárias e adoecimento, mais especificamente no concernente às complicações oriundas do adoecimento; chamando atenção para novos nichos ecológicos eleitos pelo Aedes Aegypti e a importância de soluções individuais de acesso à água potável. Cabe destacar também a falta de celeridade com relação às ações relacionadas ao saneamento ambiental, especialmente aos serviços de esgotamento sanitário que evolui mais lentamente do que o de abastecimento de água, trazendo complicações para os campos social, ambiental e econômico.

\section{REFERÊNCIAS}

ARAÚJO, S.C.;FILHO, J. A. S.; SILVA, G. M. S.; SOBRINHO, L. G. A.; NOGUEIRA, V. F. B.. Espacialização dos serviços básicos de saneamento na zona rural do município de Pombal/PB. Rev. Verde de Agroecologia e Desenvolvimento sustentável. Pombal, v.11, n.3, p.122-130, 2016.

BESERRA, E. B.; RIBEIRO, P.S.; OLIVEIRA, S. A. Flutuação populacional e comparação de métodos de coleta de Aedes (Stegomyia) aegypti (Diptera, Culicidae). Iheringia, Série Zoologia, Porto Alegre, v.104, n.4, p.418-425, 2014.

BUSATO, M.A.; ANTONIOLLI, M. A.; TEO, C. R. P. A. FERRAZ, L. Relação de Parasitoses Intestinais com as Condições de Saneamento Básico. Cienc Cuid Saúde, v.13, n.2, p.357-363. 2014.

BVS. Ministério da Saúde. Tesauro Eletrônico. Saneamento
Ambiental. 2018.

CHIARELOTTO, M.; CHIARELOTTO, M. Análise das implicações da evolução do desenvolvimento sustentável no aperfeiçoamento do saneamento ambiental. Revista Iberoamericana de Ciências Ambientais, Aracaju, v.8, n.2, p.138154, 2017.

CIRQUEIRA JÚNIOR, H.; GROSSMANN, S. M. C.; MURTA, N. M. G.; DIAS, J. V. L.; PIRES, H. H. R. Saúde em comunidade quilombola: caracterização ambiental e ocorrência de enteroparasitoses. Revista da Universidade Vale do Rio Verde, Três Corações, v.13, n.2, p.603-612, 2015.

CORRÊA, A.P.S.A. GALARDO, A. K. R.; GALARDO, C. D.; ESPINDOLA, C. B.; FARIAS, P. R. S.; MASCARENHAS, B. M. Fossas como uma nova opção de desova de Aedes 
(Stegomya) Aegypti Linnideus. Rev. Meio Ambiente e Sustentabilidade, v.9, n.4, p.298-320, 2015.

FERREIRA, M. P; GARCIA, M. S. D.. Saneamento básico: meio ambiente e dignidade humana. Dignidade Re-Vista, v.2, n.3, p.12, 2017.

GIL, L. H. S.; KATSURAGAWA, T. H.; LIMA, A. A.; TADA, M. S.; OZAKI, L. S.; JULIÃO, G. R.. Rudimentary cesspits as breeding sites for Aedes aegypti in urban areas of Northern Brazil. Rev. Pan. Amaz. Saúde, v.6, n.1, p.73-80,2015.

GOMES, S.C.S. et al. Educação em saúde como instrumento de prevenção das parasitoses intestinais no município de Grajaú - MA. Pesquisa em Foco, São Luís, v.21, n.1, p.34-45. 2016.

IBGE. Instituto Brasileiro de Geografia e Estatística. Estimativas populacionais para os municípios brasileiros. 2014.

LINHARES, E. K.; CELESTINO, A. A. Considerações sobre os casos registrados de dengue entre 2000 e 2005 e alguns fatores socioambientais na zona oeste do Rio de Janeiro. In: ENCONTRO NACIONAL DE ESTUDOS POPULACIONAIS, 15. Anais. Caxambu: ABEP, 2006.

MOTA, S. Saúde Ambiental. In: ROUQUAYROL, M.Z.; SILVA M.G. ROUQUAYROL - Epidemilogia \&Saúde. 7 ed. Rio de Janeiro: Medbook, 2013.

NAZARENO, C.; MACHADO, G.S.; VIANA, L.S. Internet ubíqua, assim como o dengue e a zica. Câmara dos Deputados: Brasília, 2016.
OMRAN, A. R. The EpidemiologicTransition: A TheoryoftheEpidemiologyofPopulationChange. The MilbankQuaterly, v.83, n.4, p.731-757, 2005.

PARAÍBA. Plano Estadual de Saúde 2016-2019. Resolução no 0123. João Pessoa:Secretaria de Estado da Saúde, 2016.

R CORE TEAM. R: a language and environment for statistical computing. Vienna: R Foundation for StatisticalComputing,2017.

REUTER, C.P.; FURTADO, L. B. F. S.; SILVA, R.; PASA, L.; KLINGER, E. I.; SANTOS, C. E.; RENNER, J. D. P.. Frequência de parasitoses intestinais: um estudo com crianças de uma creche de Santa Cruz do Sul - RS. Rev. CINERGIS, v.16, n.2, 2015. DOI:http://dx.doi.org/10.17058/cinergis.v16i2.6426

SAMBA, N.. Vigilância Epidemiológica de Doenças Infecciosas de Origem Bacteriana na Província do CuanzaNorte. Dissertação (Mestrado) - Escola Superior de Tecnologia da Saúde do Porto, 2015.

SIEGEL, S.; CASTELLAN JÚNIOR., N.J. Estatística Não Paramétrica para as Ciências do Comportamento. São Paulo: Artmed Bookman. 2006.

SILVA, M.S.F.; SANTOS, C. S.; FEITOSA, F. R. S.; SANTOS, R. D. C.. Incidência da Dengue em ambiente costeiro: uma análise do bairro Cidade Nova em Aracajú a partir dos condicionantes socioambientais. In: OS DESAFIOS DA GEOGRAFIA FÍSICA NA FRONTEIRA DO CONHECIMENTO. Anais. Campinas: Instituto de Geociências, 2017. p.17071718.

A CBPC - Companhia Brasileira de Produção Científica (CNPJ: 11.221.422/0001-03) detém os direitos materiais desta publicação. Os direitos referem-se à publicação do trabalho em qualquer parte do mundo, incluindo os direitos às renovações, expansões e disseminações da contribuição, bem como outros direitos subsidiários. Todos os trabalhos publicados eletronicamente poderão posteriormente ser publicados em coletâneas impressas sob coordenação da Sustenere Publishing, da Companhia Brasileira de Produção Científica e seus parceiros autorizados. Os (as) autores (as) preservam os direitos autorais, mas não têm permissão para a publicação da contribuição em outro meio, impresso ou digital, em português ou em tradução. 